\title{
Derecho laboral y la administración de recursos humanos
}

\author{
Labor law and human resources administration \\ Noemi Vega Lugo ${ }^{a}$, Brenda Hurtado Vega ${ }^{b}$
}

\begin{abstract}
:
One of the most important aspects of every worker is the care of their rights, throughout the years Mexico has been one of the many countries where there is legislation for the care of its workers, one that has had modifications for the sole purpose to ensure the welfare and recognition of figures such as women or professionals who are looking for work.

The development of the chosen work allowed the reader to have a complete vision of the advances in labor legislation that have taken place in the country, focusing on the 2012 reform.
\end{abstract}

Keywords:

Legislation, worker, employer

\section{Resumen:}

Uno de los aspectos más importantes de todo trabajador es el cuidado de sus derechos, a lo largo de los años México ha sido uno de los tantos países donde existe una legislación para el cuidado de sus trabajadores, misma que ha sufrido modificaciones con el único propósito de procurar el bienestar y reconocimiento de figuras como la mujer o profesionistas que están en busca de trabajo.

El desarrollo de la obra elegida permitirá dar al lector una visión completa de los avances en materia de legislación laboral que se han dado en el país, centrándose en la reforma del 2012.

Palabras Clave:

Legislación, trabajador, patron

\section{Introducción}

Juan Hernández Herrera Licenciado en Derecho en la Universidad Autónoma Nacional Autónoma de México, participó en la descentralización del área de Recursos Humanos en el Gobierno del Distrito Federal, profesor de cursos sobre Relaciones Laborales y Liderazgo, además de haber sido apoderado de empresas como Air Panamá, S.A.; Loyd, Aéreo Boliviano S.A. entre otras.

Carlos Antonio Juárez Suarez licenciado por la Universidad del Valle de México y maestro por la Escuela Superior de Contaduría y Administración del Instituto Politécnico Nacional, escritor de artículos en las revistas PyME y Laboral, impartiendo cursos sobre Relaciones Laborales; Coaching; así como Liderazgo y Planeación
Estratégica, actualmente se desempeña como asesor de empresas.

Ambos autores pretenden en esta obra ayudar a empresarios y trabajadores de todos los niveles de la organización para lograr una justicia social y permitir el equilibrio entre lo que un patrón ofrece por el trabajo realizado y lo que el trabajador recibe por el desempeño del mismo, buscando el punto medio en tre ambos actores. La obra está conformada por dieciséis capítulos mismos que de una manera clara y precisa permiten entender al lector la reforma laboral aplicada en el año 2012 y que marca el parteaguas para una relación justa y equitativa entre patrón y trabajador.

En el capítulo uno se hace una remembranza de los derechos de los trabajadores partiendo del artículo 123 constitu cional y describiendo el origen y tran sformación de

a Profesor del área académica de Turismo, Universidad Autónoma del Estado de Hidalgo, Instituto de Ciencias Económico Administrativas, https://orcid.org/0000-0001-5794-1168,Email: noemivl@uaeh.edu.mx

b Alumna del Instituto de Ciencias Sociales y Humanidades, Universidad Autónoma del Estado de Hidalgo, https://orcid.org/0000-00029164-7330,Email: brenda_sol212@hotmail.com 
la Ley Federal del Trabajo. Dentro del capítulo dos permite al lector conocer los diferentes tipos de relaciones de trabajo, su duración, estructura y elementos; observar los diferentes tipos de contratos y su diferencia con el convenio; Identificar la estructura y funcionamiento del Reglamento Interior de Trabajo, y entender las causales de recisión, así como las formas de aplicar el aviso.

Un tercer capítulo se centra en entender el concepto de jornada de trabajo, el derecho del trabajador a los días de descanso obligatorio, el derecho que posee al trabajar el día domingo, derecho a vacaciones y pago de prima vacacional, al igual que conocer las nuevas modalidades de contratación respecto a esta reforma laboral.

En un cuarto capítulo se describe, los tipos, antecedentes, y normas que protegen el salario, la base de integración del salario para la cotización ante el IMSS, además de identificar las modificaciones al salario mínimo general, profesional y la reducción en zonas económicas.

Los derechos, obligaciones y prohibiciones de patrones y trabajadores, las disposiciones de las medidas de seguridad e higiene en el centro de trabajo, la adecuación necesaria a las instalaciones para la inclusión de personal con capacidades diferentes, identificar actos de hostigamiento $\mathrm{y} / \mathrm{o}$ acoso sexual dentro y fuera del centro de trabajo, así como aspectos de la prohibición patronal para despedir a trabajadoras embarazadas o su negativa a contratarlas es visto en el capítulo cinco. Los temas abordados en el capítulo seis son los antecedentes de la capacitación y adiestramiento en México, el sustento legal de la capacitación y el adiestramiento, formación de comisiones mixtas, obligación del patrón de impartir capacitación al personal de nuevo ingreso e identificar la capacitación a que tiene derecho los trabajadores para seguir estudiando su instrucción básica, media y superior. El capítulo siete se centra en los antecedentes históricos de seguridad e higiene en el trabajo, formación de comisiones mixtas, determinación de riesgos, enfermedades y accidentes de trabajo, conocer las acciones de reconocimiento, evaluación y control de los contaminantes del ambiente laboral.

El capítulo ocho permite conocer las características, antecedentes de la seguridad social en México, así como el concepto, estructura y funcionamiento del IMSS, el ISSSTE, INFONAVIT, FOVISSSTE y AFORE. El capítulo nueve se centra en el reparto de utilidades con temas como obligaciones y excepciones para su pago, factores que los determinan y obligaciones de los sindicatos sobre este tema.

Dentro del capítulo diez cita todo lo relacionado a la antigüedad de los trabajadores, derechos que genera, derechos de preferencia a los ascensos y mejora de las obligaciones del patrón para indemnizar al trabajador que se considere con el derecho preferencial. El capítulo número once recapitula los antecedentes de trabajo de mujeres y menores de edad, las obligaciones de los trabajadores y de los patrones en lo que dura la relación laboral, comprender la importancia sobre el trabajo de la mujer embarazada e identificar las prohibiciones por parte de los patrones para exigir un certificado médico de no embarazo.

El capítulo doce sitúa al lector en la posibilidad de observar la diferencia entre trabajadores sindicalizados y de confianza y los apartados A y B del Artículo 123 constitucional. El capítulo trece describe los antecedentes de los sindicatos en México, la naturaleza legal de las relaciones colectivas de trabajo, estructura, registro y funcionamiento de los sindicatos, así como los derechos, obligaciones y prohibiciones de los mismos.

En el capítulo catorce se menciona el concepto, antecedentes, objetivos, requisitos, proceso y terminación de la huelga, en el capítulo quince se mencionan los trabajadores del campo, trabajos a distancia o en el dominio del trabajador y trabajadoras domésticas.

Para cerrar con el capítulo dieciséis que toca lo referente a las autoridades laborales y procedimientos ante las mismas.

Como podrá darse cuenta esta obra es bastante completa, ideal para ser tomada como libro te texto para carreras como administración o derecho, la información que contiene permite de manera sencilla hacer una línea del tiempo completa de las modificaciones que han sufrido a lo largo del tiempo en el país los derechos de los trabajadores, contrastan do con la realidad y permitiendoa las nuevas generaciones hacer propuestas para alcanzar un país productivo y con una verdadera justicia social y laboral.

\section{Referencias}

[1] Hernandez , J., \& Juárez, C. (2015). Derecho laboraly la administración de recursos humanos. Mexico : Grupo Editorial Patria. 